\title{
Simulation of Ball-nose End Milling Operations - Selection of Geometric Resolution Parameters
}

\author{
Ciro A. Rodríguez \\ Instituto Tecnológico y de Estudios Superiores de Monterrey, MEXICO \\ Taylan Altan \\ The Ohio State University, USA
}

Key words: CAD/CAM, 3-axis NC machining, sculptured surfaces, ball-nose end mill, Z-map

Abstract: Ball-nose end milling operations are extensively used for 3-axis machining of sculptured surfaces. The process variables, such as chip thickness distribution and cutting speed distribution, can be simulated by means of discrete representation of the workpiece surface and the cutting tool. In the current approach, the workpiece surface is represented with a Zmap. The cutting edge of the tool is represented by a set of nodes. The purpose of this work was to develop a methodology for selecting the geometric resolution parameters required by the workpiece and the cutting tool. The selection criteria include: a) a prescribed amount of error in the prediction of the chip thickness and cutting speed and b) minimization of computation time. The current methodology is demonstrated for a finish milling operation with a ball-nose end mill.

\section{INTRODUCTION}

Ball-nose end mills are used for the generation of sculptured surfaces, such as those found in dies and molds. The analysis and optimization of NC programs for ball-nose end milling can be approached with continuous or discrete geometric representation of the workpiece geometry.

Several research groups have developed systems for the simulation of ball-nose end milling based on a continuous geometric representation: [Eversheim; 1990] [Lim; 1997a] [Lim; 1997b] [Park; 1993] [Yang; 1993]. These systems allow fast computation time. However, the geometric history of the workpiece can not be handled properly, especially when the production of sculptured surfaces requires roughing and semi-finishing operations with flat end mill or bull-nose end mill.

Those systems that use a discrete geometric representation of the workpiece include: [Fussell; 1992] [Jerard; 1990] [Jerard; 1989] [Mizugaki; 1994] [Yamazaki; 1995] [Yamazaki; 1991]. The system for the simulation of ball-nose end milling described in this study is also based on a discrete geometric representation: [Bergs; 1996] [Rodríguez; 1997].

In general, the discrete geometric representation of the workpiece implies a trade-off between prediction accuracy and computation time for different levels of geometric resolution [Drysdale; 1991]. The purpose of this work was to develop a methodology for selecting the geometric resolution parameters required by the workpiece and the cutting tool. The objective is to maintain a prescribed amount of error in the prediction of the chip thickness and cutting speed, while minimizing of computation time, for a given $\mathrm{NC}$ program.

\section{CHIP GEOMETRY}

Figure 1 shows a ball-nose end milling operation on a flat surface and the corresponding nomenclature (NOTE: for simplicity, the term chip geometry throughout this work refers to the undeformed condition). In the case of the ball-nose end mill, the chip thickness vector is

The original version of this chapter was revised: The copyright line was incorrect. This has been corrected. The Erratum to this chapter is available at DOI: 10.1007/978-0-387-35392-0_40 
defined by the rotation angle $(\phi)$ (Figure 1-Top View) and the cutting edge angle ( $\kappa$ ) (Figure 1-Section A-A).
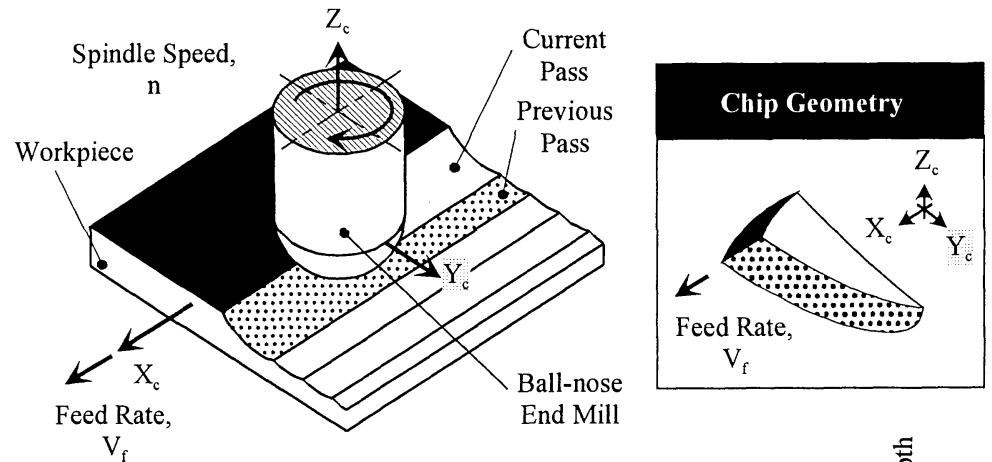

\section{TOP VIEW}
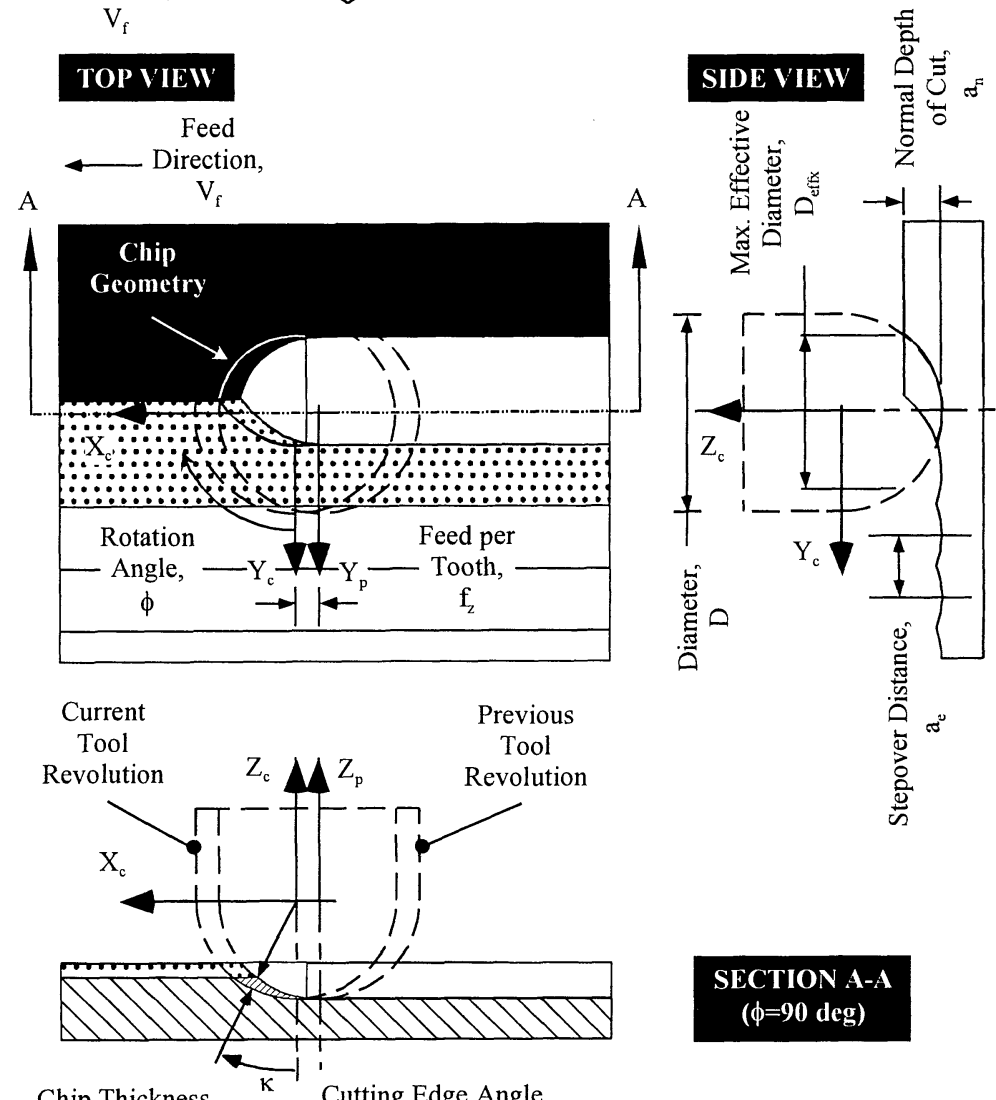

Chip Thickness,

Cutting Edge Angle,

$\mathrm{h}$

$$
h(\phi, \kappa)=\left(\frac{D}{2}\right)+f_{z} \sin \phi \sin \kappa-\sqrt{\left(\frac{D}{2}\right)^{2}-f_{z}^{2}\left(1-\sin ^{2} \phi \sin ^{2} \kappa\right)}
$$

Figure 1. Ball-nose end milling operation - nomenclature 
When a ball-nose end mill is used on sculptured surfaces with a 3-axis machining center, the tool engages the workpiece at different angles relative to the surface normal. The relative angle between the tool axis and the surface normal can be defined in terms of two components: lead angle $\left(\beta_{\mathrm{f}}\right)$ and tilt angle $\left(\beta_{\mathrm{fN}}\right)$. These angles are measured in the feed direction and perpendicular to the feed direction, respectively.

In order to have a meaningful analysis of the milling processes in sculptured surface production, it is necessary to keep track of the geometric history of the workpiece. Therefore, for every tool motion, the workpiece geometry needs to be updated. For that purpose, a mesh of points, stored as a $2 \mathrm{D}$ array of $\mathrm{Z}$ coordinates or Z-map, represents the workpiece geometry (see Figure 2). For each tool interpolation the swept volume generated by the tool is used to find those workpiece points that need to be updated.

The cutting edge geometry is represented by a set of nodes along the cutting edge (see Figure 2). The engaged cutting edge nodes (i.e., cutting edge nodes that penetrate the workpiece material) are found by comparing the height of the cutting edge node ( $\mathrm{z}$ coordinate) to the height of the neighboring mesh points that represent the workpiece. Once an engaged cutting edge node is found, an analytical expression (as shown in Figure 1) is used to compute the chip thickness at that particular angular position. If the node is not engaged, chip thickness is set to zero [Röders; 1989] [Rodríguez; 1997] [Koch; 1990].

The chip thickness profile is determined by computing the instantaneous chip thickness of all the nodes along the cutting edge, for all tool rotation positions (as shown in Figure 2). The maximum values for chip thickness and cutting speed are computed based on the chip thickness profile:

- Maximum Chip Thickness $\left(\mathrm{h}_{\max }\right)$. This is the largest value of chip thickness in the complete profile.

- Maximum Cutting Speed $\left(\mathrm{V}_{\mathrm{cmax}}\right)$. Based on the chip thickness profile, the highest engaged node (with respect to the tool tip) can be determined for all rotation positions. The highest engaged node is then used to compute the maximum effective diameter $\left(\mathrm{D}_{\text {effix }}\right)$ and associated maximum cutting speed $\left(\mathrm{V}_{\mathrm{cmax}}\right)$.
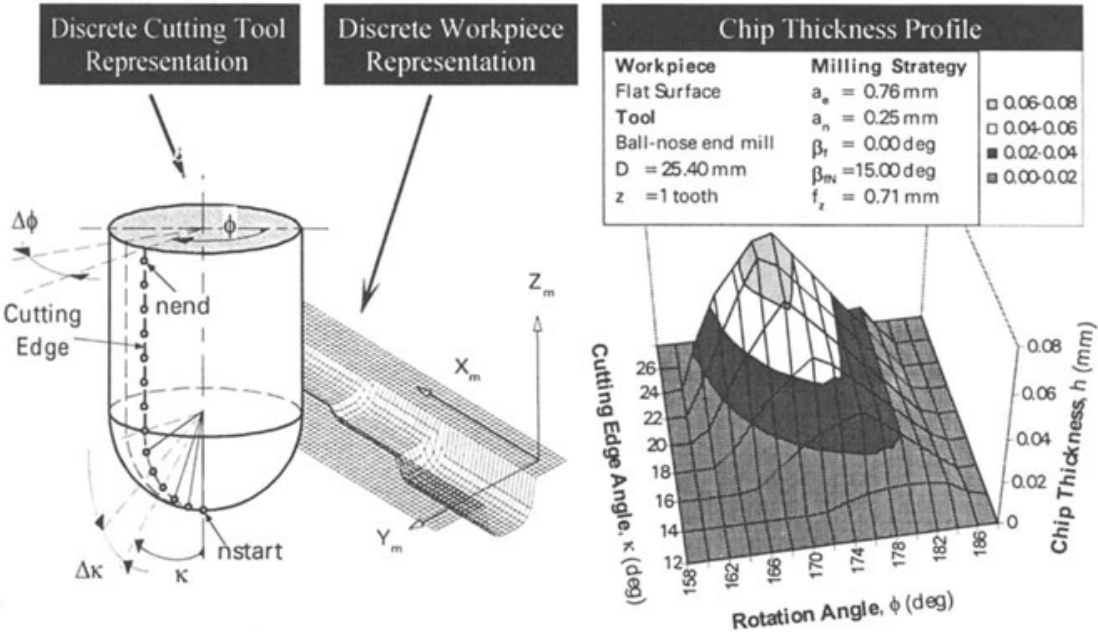

Figure 2. Chip thickness profile with ball-nose end mill 


\section{PREDICTION ERROR AND COMPUTATION TIME}

The discrete geometry of the workpiece and the cutting edge are controlled with the following parameters:

- Workpiece resolution is defined as the distance between the points of the Z-map that represents the workpiece surface $(\Delta x=\Delta y)$.

- Cutting edge resolution is defined as the increment in rotation angle and cutting edge angle $(\Delta \phi=\Delta \kappa)$.

Because of the discrete nature of the workpiece and the cutting edge geometry, the prediction of maximum chip thickness $\left(\mathrm{h}_{\max }\right)$ and maximum cutting speed $\left(\mathrm{V}_{\text {cmax }}\right)$ contains some error. In this work, the prediction error $\left(\mathrm{E}_{\mathrm{hmax}}\right)$ is defined as the deviation of the predicted value for maximum chip thickness $\left(\mathrm{h}_{\max }\right)$ with respect to the actual value.

\subsection{Prediction Error}

In order to study the influence of geometric resolution parameters (cutting edge and workpiece) on the accuracy of chip thickness prediction, it is necessary to analyze a large number of NC programs. The algorithms for computation of chip thickness profile (as shown in Figure 2) were implemented in MATLAB programs, in order to avoid the direct use of NC programs. This approach allowed more flexibility and comprehensiveness to the study of chip thickness prediction error.

The predictions for maximum chip thickness and maximum cutting speeds were conducted for cases with different combinations of process parameters (i.e., tool diameter, depth of cut, etc.), cutting tool resolution $(\Delta \phi=\Delta \kappa)$, and workpiece resolution $(\Delta x=\Delta y)$, as shown by this table:

\begin{tabular}{|l|l|l|l|}
\hline Variable Factors & Constant Factors \\
\hline Ball-nose end mill dia. $(\mathrm{D}):$ & 25.4 and $50.8 \mathrm{~mm}$ & Workpiece geometry & Flat \\
\hline Depth of cut $\left(\mathrm{a}_{\mathrm{n}}\right):$ & 0.25 and $0.5 \mathrm{~mm}$ & Feed per tooth $\left(\mathrm{f}_{\mathrm{z}}\right)$ & $0.5 \mathrm{~mm}$ \\
\hline Stepover distance $\left(\mathrm{a}_{\mathrm{e}}\right):$ & 0.50 and $1.0 \mathrm{~mm}$ & Lead angle $\left(\beta_{\mathrm{f}}\right)$ & $0 \mathrm{deg}$ \\
\hline Workpiece resolution $(\Delta \mathrm{x}=\Delta \mathrm{y}):$ & $0.1,0.5$ and $1.0 \mathrm{~mm}$ & Tilt angle $\left(\beta_{\mathrm{fN}}\right)$ & $0 \mathrm{deg}$ \\
\hline Tool resolution $(\Delta \phi=\Delta \kappa):$ & $0.5,1.0$ and $2.0 \mathrm{deg}$. & & \\
\hline
\end{tabular}

For a given analysis point along the tool path, the relative position and orientation of the workpiece mesh influence the prediction of chip thickness profile. This results in a distribution of prediction error, for a given analysis point along the tool path. Therefore, for each set of process and geometric resolution parameters there is a maximum prediction error $\left(\mathrm{X}_{\mathrm{hmax}}\right)$.

A linear regression was conducted to derive an expression that relates the maximum prediction error $\left(\mathrm{X}_{\mathrm{hmax}}\right)$ to the process parameters and resolution parameters (see Equation 1). The location of the maximum chip thickness vector (determined by $\phi_{\text {hmax }}$ and $\kappa_{\text {hmax }}$ ) represents the combination of large number of process variables: tool diameter (D), depth of cut $\left(a_{n}\right)$, stepover distance $\left(\mathrm{a}_{\mathrm{e}}\right)$ and feed per tooth $\left(\mathrm{f}_{\mathrm{z}}\right)$.

$$
\begin{gathered}
X_{h \max }=-10.4-0.421 D+0.193 \phi_{h \max }-0.610 \kappa_{h \max }+16.0 \Delta x+1.51 \Delta \phi \\
\text { where, } \Delta \mathrm{x}=\Delta \mathrm{y}, \Delta \phi=\Delta \kappa \text { and } R_{a d j}^{2}=90.5 \%
\end{gathered}
$$

The maximum prediction error of maximum cutting speed was smaller (in most of the cases) than the one for maximum chip thickness. Therefore, Equation 1 can be assumed to be appropriate to estimate the maximum prediction error for both process variables $\left(\mathrm{V}_{\mathrm{cmax}}\right.$ and $\left.\mathrm{h}_{\max }\right)$. 
Figure 3 shows a 3D plot of Equation 1, for a given set of process conditions. The intersecting planes with a fixed level of maximum prediction error $\left(\mathrm{X}_{\mathrm{hmax}}\right)$ show that the same amount of maximum prediction error can be obtained with different combinations of workpiece and cutting edge resolution.

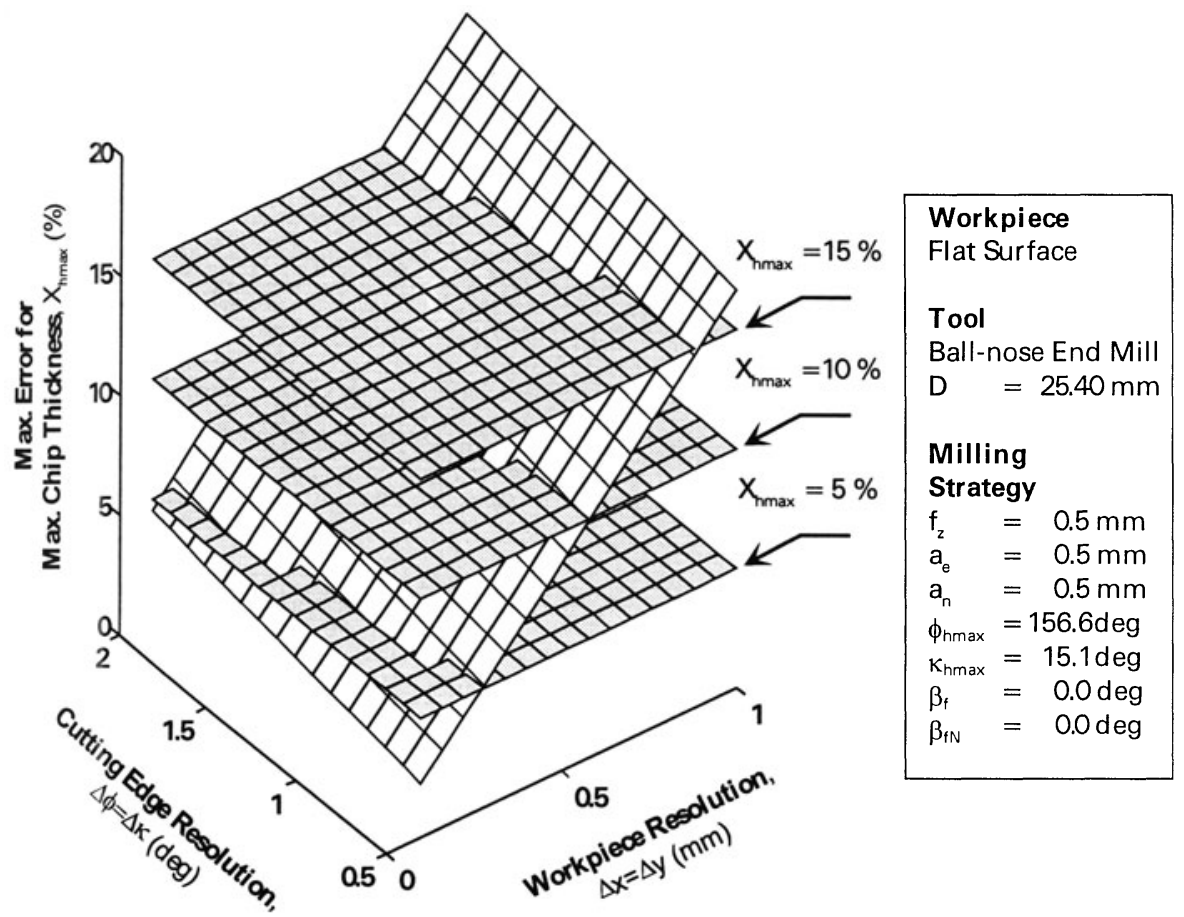

Figure 3. Influence of workpiece resolution $(\Delta x=\Delta y)$ and cutting edge resolution $(\Delta \phi=\Delta \kappa)$ on the max. prediction error of max. chip thickness $\left(\mathrm{X}_{\mathrm{hmax}}\right)$

\subsection{Computation Time}

The existing algorithms for computation of the chip thickness and cutting speed profiles and for updating of the workpiece geometry were analyzed to determine the influence of the resolution parameters on the computation time. By inspection of these algorithms, it was determined that the computation time for analysis of a given NC program can be estimated with an expression of the following form:

$$
t_{r m n}=a_{0}+\frac{a_{1}}{\Delta x^{2}}+\frac{a_{2}}{\Delta \phi^{2}}
$$

where, $\Delta x=\Delta y$ and $\Delta \phi=\Delta \kappa$

The coefficient $a_{0}$ is related to computational overhead. The coefficient $a_{1}$ is related to the number of points in the workpiece mesh that need to be updated. Finally, the coefficient $\mathrm{a}_{2}$ is related to the number of nodes defined along the cutting edge. All three coefficients depend also on the inherent speed of a particular CPU.

Different values of computation time $\left(\mathrm{t}_{\mathrm{run}}\right)$ are recorded by analyzing a given NC program with the algorithms described in Section 2, for different combinations of workpiece resolution $(\Delta \mathrm{x}=\Delta \mathrm{y})$ and cutting edge resolution $(\Delta \phi=\Delta \kappa)$. The coefficients in Equation 2 are then 
determined through a linear regression that relates the influence of $\Delta x$ and $\Delta \phi$ on the computation time $\left(\mathrm{t}_{\mathrm{run}}\right)$.

\section{SELECTION OF RESOLUTION PARAMETERS}

\subsection{Procedure}

Using the expressions for estimating the maximum prediction error $\left(\mathrm{X}_{\mathrm{hmax}}\right)$ and the expected computation time $\left(\mathrm{t}_{\mathrm{run}}\right)$, it is possible to select the appropriate workpiece mesh resolution $(\Delta x=\Delta y)$ and cutting tool resolution $(\Delta \phi=\Delta \kappa)$ to obtain a prescribed level of maximum prediction error, while minimizing the computation time.

An expression for the maximum prediction error produced for the maximum chip thickness $\left(\mathrm{X}_{\mathrm{hmax}}\right)$ was determined through direct testing of the algorithms for computation of chip thickness profile (see Equation 1). For a given tool diameter and chip geometry (i.e., location of the maximum chip thickness vector), the expression shown in Equation 1 can be written in the following form:

$$
X_{h \text { max }}=b_{0}+b_{1} \Delta x+b_{2} \Delta \phi
$$

where, $\Delta x=\Delta y$ and $\Delta \phi=\Delta \kappa$

Specific values of tool diameter (D) and maximum chip thickness vector $\left(\phi_{\text {hmax }}\right.$ and $\left.\kappa_{\text {hmax }}\right)$ need to be selected, in order to reduce Equation 1 to Equation 3, where $X_{h \max }$ is only a function of $\Delta \mathrm{x}$ and $\Delta \phi$.

According to Equation 3, the same amount of maximum prediction error $\left(\mathrm{X}_{\mathrm{hmax}}\right)$ can be achieved with different combinations of workpiece resolution $(\Delta x=\Delta y)$ and cutting tool resolution $(\Delta \phi=\Delta \kappa)$. Such combinations can be represented with the following linear equation:

$$
\Delta \phi=\frac{1}{b_{2}} X_{h \max }-\frac{b_{0}}{b_{2}}-\frac{b_{1}}{b_{2}} \Delta x
$$

where, $\Delta x=\Delta y$ and $\Delta \phi=\Delta \kappa$

By combining Equations 2 and 4, the following expression is obtained:

$$
t_{r u n}=a_{0}+a_{1} \Delta x^{-2}+a_{2}\left[\left(\frac{1}{b_{2}}\right) X_{h \max }-\left(\frac{b_{0}}{b_{2}}\right)-\left(\frac{b_{1}}{b_{2}}\right) \Delta x\right]^{-2}
$$

where, $\Delta x=\Delta y$ and $\Delta \phi=\Delta \kappa$

Then, the expression for workpiece resolution $(\Delta x=\Delta y)$ that minimizes computation time $\left(\mathrm{t}_{\mathrm{run}}\right)$ is obtained with the following partial derivative:

$$
\frac{\partial t_{r u n}}{\partial \Delta x}=-2 a_{1} \Delta x^{-3}+2 a_{2}\left(\frac{b_{1}}{b_{2}}\right)\left[\left(\frac{1}{b_{2}}\right) X_{h \max }-\left(\frac{b_{0}}{b_{2}}\right)-\left(\frac{b_{1}}{b_{2}}\right) \Delta x\right]^{-3}=0
$$

where, $\Delta x=\Delta y$ and $\Delta \phi=\Delta \kappa$

The final expression is the following:

$$
\Delta x @ t_{r m-\min }=\frac{\left(\frac{1}{b_{2}}\right) X_{h \max }-\left(\frac{b_{0}}{b_{2}}\right)}{\left(\frac{a_{2}}{a_{1}}\right)^{\frac{1}{3}}\left(\frac{b_{1}}{b_{2}}\right)^{\frac{1}{3}}+\left(\frac{b_{1}}{b_{2}}\right)}
$$


where, $\Delta x @ t_{r u n-\min }=\Delta y @ t_{r u n-\min }$

The corresponding cutting edge resolution for the minimum computation time $\left(\Delta \phi @ \mathrm{t}_{\mathrm{run}-}\right.$ $\min$ and $\left.\Delta \kappa @ \mathrm{t}_{\text {run-min }}\right)$ is obtained by combining Equations 7 and 4.

\subsection{Application Example}

In order to demonstrate the procedure described in the previous section, the coefficients of Equation 2 were obtained based on the computation times required for chip geometry analysis in a simple NC program. This NC program contains 10 passes, with the parameters shown in Figure 4.

The computation times for different combinations of workpiece and cutting tool resolution were collected. Then, a regression analysis was used to find the coefficients required in Equation 2 (plotted in Figure 4).

The results of the procedure described in Section 4.1 are shown in Figure 5, which shows the effect of workpiece mesh resolution on computation time for different levels of maximum prediction error. In Figure 5-A, for a given level of maximum prediction error $\left(\mathrm{X}_{\mathrm{hmax}}\right)$ of $10 \%$, the computation time is minimized at a workpiece resolution $(\Delta \mathrm{x}=\Delta \mathrm{y})$ of $0.4 \mathrm{~mm}$. The curve that joins all the minimum computation times (for different levels of maximum prediction error) is also indicated $\left(\mathrm{t}_{\text {run-min }}\right)$. Figure $5-\mathrm{B}$ shows the combination of workpiece $(\Delta \mathrm{x}=\Delta \mathrm{y})$ and cutting tool resolution $(\Delta \phi=\Delta \kappa)$ that minimizes computation time $\left(\mathrm{t}_{\mathrm{run}}\right)$.

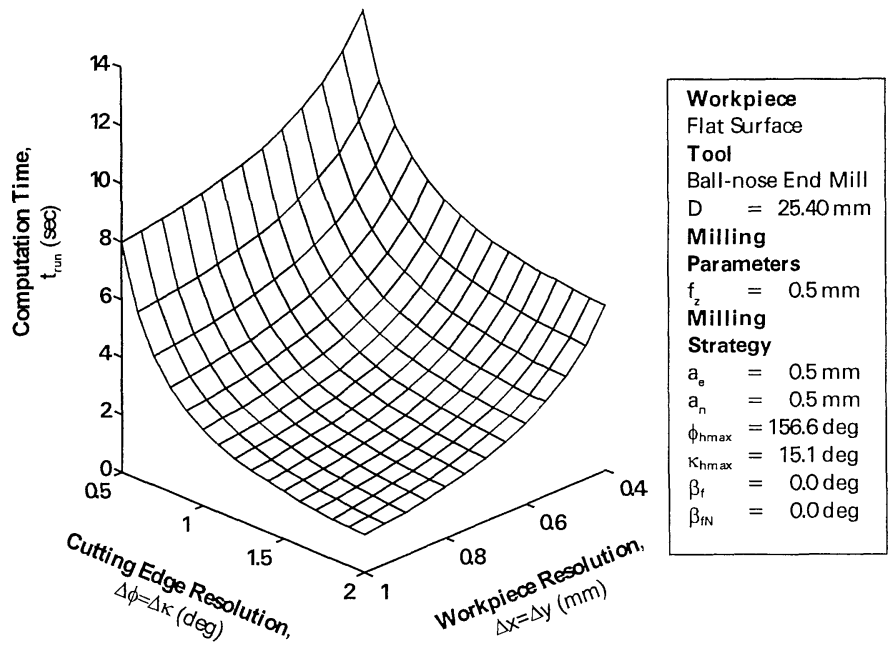

Figure 4. Influence of workpiece resolution $(\Delta x=\Delta y)$ and cutting edge resolution $(\Delta \phi=\Delta \kappa)$ on the computation time $\left(\mathrm{t}_{\mathrm{run}}\right)$

In summary, for a maximum prediction error $\left(\mathrm{X}_{\mathrm{hmax}}\right)$ of $10 \%$, computation time in minimized with the following resolution parameters (with a given NC program):

- Workpiece resolution: $\Delta x=\Delta y=0.4 \mathrm{~mm}$.

- Cutting edge resolution: $\Delta \phi=\Delta \kappa=2.5 \mathrm{deg}$. 


\section{DISCUSSION}

This work has shown a viable approach for the selection of geometric resolution parameters in the simulation of ball-nose end milling operations with discrete representation of workpiece and cutting edge geometry. In order to achieve a prescribed level of prediction error, while minimizing computation time, it is necessary to have mathematical expressions for the influence of geometric resolution parameters on a) the prediction error and b) the computation time.

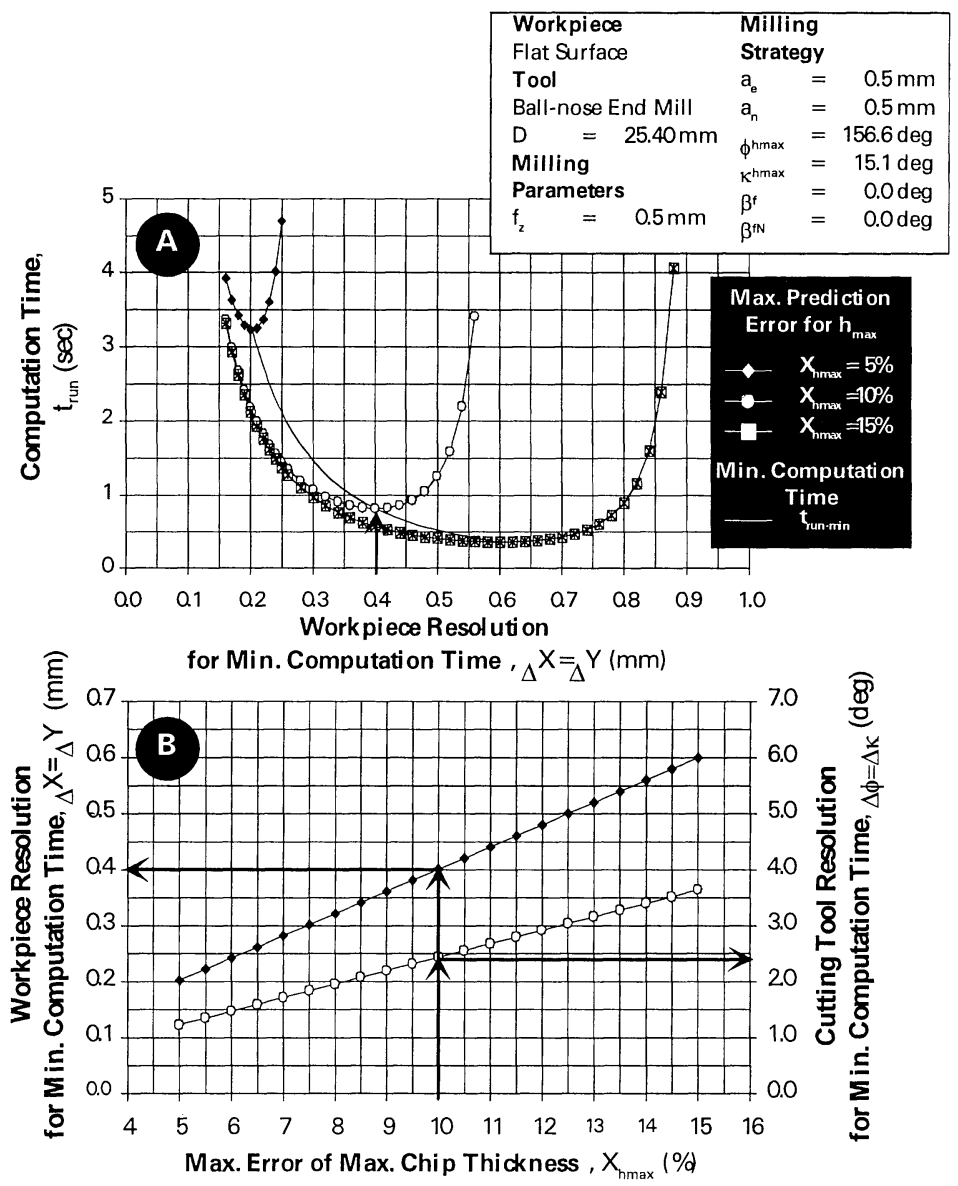

Figure 5. Influence of workpiece resolution $(\Delta \mathrm{x}=\Delta \mathrm{y})$ and cutting edge resolution $(\Delta \phi=\Delta \kappa)$ on the computation time $\left(\mathrm{t}_{\mathrm{nun}}\right)$ for different levels of maximum prediction error $\left(\mathrm{X}_{\mathrm{hmax}}\right)$

The expression for prediction error was generated by extensive testing of the algorithms for computation of the chip thickness profile. In order to determine the maximum prediction error, especial consideration was given to the relative position and orientation of the workpiece mesh with respect to the analysis point along the tool path.

The expression for maximum prediction error shown in Equation 1 is valid for a wide range of process parameters in finish milling operations with ball-nose end mill. Currently, this expression is valuable in selecting geometric resolution parameters for milling operations of flat surfaces, with the tool axis parallel to the surface normal. Therefore, this expression 
needs to be extended to consider different combinations of tilt and lead angle, as encountered in 3-axis milling of sculptured surfaces.

Direct testing of a sample NC program and measurement of the computation time generated the expression for computation time. In the example shown, Equation 2 provided an excellent correlation between the geometric resolution parameters and the computation time. This indicates that the form of this equation is correct. For future work, it should be possible to have approximate expressions to determine the coefficients in Equation 2 by estimating the number of workpiece points that need update and the number of cutting edge nodes required for the cutting tool.

\section{REFERENCES}

[Bergs; 1996] Bergs, Thomas; Rodríguez, Ciro A.; Altan, Taylan; Altintas, Yusuf, "Tool Path Optimization for Finish Milling of Die and Mold Surfaces - Software Development", T. of NAMRI/SME, 1996, pp. 81-86

[Drysdale; 1991] Drysdale, Robert L.; Quinn, Jerome L.; Ozair, Kamran; Jerard, Robert B., "Discrete Surface Representation for Simulation Verification, and Generation of Numerical Control Programs", Proceedings of the 1991 NSF Design and Manufacturing Systems Conference, Austin, Texas, January, 1991, pp. 431-438

[Eversheim; 1990] Eversheim, W.; Cobanoglu, M. T., "NC-Programmierung für das Fräsen von Schmiedegesenken - CAD/CAM-Systeme noch ausbaufähig", Indutrie-Anzeiger, vol. 39, 1990, pp. $18,21-23$

[Fussell; 1992] Fussell, B. K.; Ersoy, C.; Jerard, R. B., "Computer Generated CNC Machining Feedrates", Proceedings of the 1992 Japan-USA Symposium on Flexible Automation - Volume 1, ASME, San Francisco, CA; July, 1992, pp. 377-384

[Jerard; 1990] Jerard, Robert. B.; Angleton, Jennifer M.; Drysdale, Robert L.; Su, Peter, " The Use of Surface Points Sets for Generation, Simulation, Verification, and Automatic Correction of NC Machining Programs", Proceedings of NSF Design and Manufacturing Systems Conference, Tempe, Arizona, 1990 pp. 143-148

[Jerard; 1989] Jerard, Robert B.; Drysdale, Robert L.; Hauck, Kenneth; Schaudt, Barry; Magewick, John;, "Methods for Detecting Errors in Numerically Controlled Machining of Sculptured Surfaces"; IEEE Computer Graphics \& Applications, 1989, pp. 26-39

[Koch; 1990] Koch, Karl-Friedrich; Lilly, Blaine; Kropp, Eric; Altan, Taylan, Development of a CAEModule for Calculating Forces in 3-Axis Milling of Sculptured Surfaces in Die Manufacturing, Engineering Research Center for Net Shape Manufacturing (The Ohio State University), Report ERC/NSM-D-90-43, December, 1990

[Lim; 1997a] Lim, Ee Meng; Menq, Chia-Hsiang, "Integrated Planning for Precision Machining of Complex Surfaces. Part 1: Cutting-Path and Feedrate Optimization", Int. J. Mach. Tools Manufact., Vol. 37, No. 1, 1997, pp. 61-75

[Lim; 1997b] Lim, Ee Meng; Menq, Chia-Hsiang, "Integrated Planning for Precision Machining of Complex Surfaces. Part 2: Application to the Machining of a Turbine Blade Die", Int. J. Mach. Tools Manufact., Vol. 37, No. 1, 1997, pp. 77-91

[Mizugaki; 1994] Mizugaki, Y.; Hao, M.; Sakamoto, M.; Makino, H.; "Optimal Tool Selection based on Generic Algorithm in a Geometric Cutting Simulation", Annals of the CIRP, Vol. 43/1/1994, pp. 433436

[Park; 1993] Park, Sehyung; Jun, Yong-Tae; Lee, Chong-Won; Yang, Min-Yang, "Determining the Cutting Conditions for Sculptured Surface Machining", Int. J. of Advanced Manufacturing Technology, Vol. 8, 1993, pp. 61-70

[Röders; 1989] Röders, Jürger, Simulation der Eingriffsverhältnisse beim Fräsen mit Kugelkopffräsern mit beliebieger Schneidengeometrie, Diplomarbeit, March 29, 1989, WZL, Technical University of Aachen, Germany

[Rodríguez; 1997]Rodríguez, Ciro A., Ball-nose End Milling - Development of Criteria for Automatic Selection of Spindle Speed and Feed Rate, Ph.D. Dissertation, The Ohio State University, 1997

[Yamazaki; 1995] Yamazaki, K.; Kawahara, Y.; Jeng, J-C.; Aoyama, H., "Autonomous Process Planning with Real-Time Machining for Productive Sculptured Surface Manufacturing Based on Recognition of Geometric Features", Annals of the CIRP, Vol. 44 / 1 / 1995, pp. 439-444 
[Yamazaki; 1991] Yamazaki, K.; Kojima, N.; Sakamoto, C.; Saito, T., "Real-Time Model Reference Adaptive Control of 3-D Sculptured Surface Machining", Annals of the CIRP, Vol. 40 / 1 / 1991, pp. 479-482.

[Yang; 1993] Yang, M. Y.; Sim, C. G., "Reduction of Machining Errors by Adjustment of Feedrates in the Ball-end Milling Process", Int. J. Prod. Res., Vol. 31, No. 3, 1993, pp. 665-689 